(c) The Author(s) 2016. This is an Open Access article, distributed under the terms of the Creative Commons Attribution licence (http://creativecommons. org/licenses/by/4.0/), which permits unrestricted re-use, distribution, and reproduction in any medium, provided the original work is properly cited.

\title{
Landslide-generated tsunami and particle transport in mountain lakes and reservoirs
}

\author{
Jeevan KAFLE, ${ }^{1,2}$ Puskar R. POKHREL, ${ }^{1,3}$ Khim B. KHATTRI, ${ }^{1}$ Parameshwari KATTEL, ${ }^{1,4}$ \\ Bhadra Man TULADHAR, ${ }^{1}$ Shiva P. PUDASAINI ${ }^{5}$ \\ ${ }^{1}$ School of Science, Kathmandu University, Dhulikhel, Kavre, Nepal \\ ${ }^{2}$ Department of Mathematics, Nepal Sanskrit University, Kathmandu, Nepal \\ ${ }^{3}$ Department of Mathematics, R.R. Campus, Tribhuvan University, Kathmandu, Nepal \\ ${ }^{4}$ Department of Mathematics, Tri-Chandra Multiple Campus, Tribhuvan University, Kathmandu, Nepal \\ ${ }^{5}$ Department of Geophysics, Steinmann Institute, University of Bonn, Bonn, Germany \\ Correspondence: Jeevan Kafle <jkafle@student.ku.edu.np>
}

\begin{abstract}
Gravitational mass flows may generate tsunamis as they hit water bodies such as oceans, reservoirs or mountain lakes. Upon impact, they can generate tremendous particle-laden or debris flows and floods. Rapidly cascading waves down mountain slopes can trigger debris flows or floods, potentially causing huge damage to civil structures and endangering life. Here we apply a general twophase mass flow model (Pudasaini, 2012), and present three-dimensional (3-D), high-resolution simulations for a real two-phase debris impacting a fluid reservoir. An innovative formulation provides an opportunity, within a single framework, to simulate simultaneously the sliding two-phase debris/ landslide, reservoir, debris impact at reservoir, water-wave generation, propagation and mixing, and separation between solid and fluid phases. The results demonstrate formation and propagation of very special solid and fluid structures in the reservoir, propagation of submarine debris, turbidity currents, and complex interactions between the subaerial debris, surface tsunami and submarine debris waves. Our results reveal that the submerge timescaling for a deformable two-phase debris deviates substantially from the same for a non-deformable solid. These results substantially increase our understanding of 3-D complex multiphase systems/flows. This allows for the proper modeling of landslide/debris-induced mountain tsunami, dynamics of turbidity currents and highly concentrated sediment transports in Himalayan and Alpine slopes and channels, with associated applications to engineering, environmental and hazard-mitigation plans.
\end{abstract}

KEYWORDS: geomorphology, glacier hazards, glacier modeling, sedimentology

\section{INTRODUCTION}

Landslides, debris flows, mud-flows, rockfalls, snow, ice and rock avalanches and tsunamis are common geophysical mass flow events in mountainous and coastal regions (Pudasaini and Hutter, 2007). Recent records clearly indicate that the high Himalayan regions are increasingly prone to devastating snow avalanches, landslides, debris flows and rockfalls (Kafle, 2014). The Jure landslide of 2 August 2014 in central-north Nepal, and other avalanches and landslides including those in the Mount Langtang and Everest areas triggered by the 2015 great Nepal earthquakes (25 April and 12 May) are recent events that have awakened the Nepalese scientific community to the need for systematic research. In the context of a mountainous country like Nepal, there is an urgent need to initiate advanced scientific research to understand the initiation mechanics of these events, their complex flow dynamics, impacts on the society and civil structures, and also the design, development and application of appropriate mitigation measures, hazard mappings and planning (Masson and others, 2006).

There are hundreds of large mountain rivers and lakes, including glacial lakes, in the Himalaya. Several reservoirs have also been created for hydroelectric power generation in Nepal and neighboring countries (Shrestha and others, 2010; Petrakov and others, 2011; Worni and others, 2012;
Miao and others, 2014). These may be severely affected by avalanching from hanging glaciers, landslides, debris flows and rockslides, which can trigger glacial lake outburst floods and tremendous water waves (mountain tsunamis), debris flows and mud-flows.

Tsunamis are long water waves triggered by a sudden disturbance of the floor or surface of a water body (e.g. ocean, bays, sea or lakes) and are generally caused by earthquakes, volcanic eruptions, asteroid impacts or landslides. Tsunamis can produce high wave run-ups sufficient to flood areas far inland from the shore of the water body, thereby threatening the coastal population and destroying coastal infrastructures (Grilli and others, 2002; Fritz and others, 2004; Haugen and others, 2005; Masson and others, 2006; Fritz and Kalligeris, 2008; Cecioni, 2010; Mohammed and Fritz, 2012). Although landslide-generated tsunamis are less frequent, they can cause more local threats than earthquake-generated tsunamis (Grilli and others, 2007; Viroulet and others, 2013). They can induce mega-tsunamis with extreme run-up heights. Examples include tsunamis in Lituya Bay, Alaska, USA (1958; Miller, 1960; Fritz and others, 2009), Vajont, Italy (1963; Miller, 1964), and Spirit Lake, Washington, USA (1980; Glicken and others, 1989).

When subaerial landslides fall into a water body, impulsive water waves are formed together with submarine 
(subaqueous) landslides (Ataie-Ashtiani and Shobeyri, 2008). Because of the strong phase interactions between the landslide and fluid (water), non-trivial rheology and complicated slopes, proper modeling of the dynamics of these events is challenging (Viroulet and others, 2013; Pudasaini, 2014). In the past, several analytical methods have been proposed to calculate the wave height (Murty, 1979), velocity of a submerged solid (Pelinovsky and Poplavsky, 1996; Watts, 1997), wave velocity along a plane beach (Sammarco and Renzi, 2008), and the dynamics of tsunamis generated by submarine (subaqueous) landslides of changing volume in a variable basin (Didenkulova and others, 2010), to name a few. Several experiments were performed with solid slides to measure the impacts, splash, impulse waves, dynamics and interactions between the slide and the water body. Experimental apparatus included a solid box generating subaerial landslides (Law and Brebner, 1968), a tray rolling down a roller ramp (Kamphuis and Bowering, 1972), solid blocks sliding down a flume into a body of water kept in a reservoir (Walder and others, 2003), and three-dimensional (3-D) submarine landslides (Enet and others, 2007). Similarly, experiments were carried out with accelerating bulk granular materials (Mohammed and Fritz, 2012), and rigid-deformable slides (Ataie-Ashtiani and NikKhah, 2008). For the numerical simulations, largely and effectively single-phase shallow-water and/or granular flow models have been used to describe fluid and slide motions, tsunami and submarine landslides. These simulations have been based on the incompressible Navier-Stokes equations (Heinrich, 1992), shallow-water equations (Heinrich and others, 2001), smoothed particle hydrodynamics (Monaghan and Kos, 2000), the finite-volume method for 3-D slides (Liu and others, 2005), and a finite-volume method based on multiple-fluid Navier-Stokes equations (Abadie and others, 2010). Although substantial advancements have been made in the past, none of these events and their associated dynamics, and impacts on the society, are satisfactorily investigated yet. The development and applications of the mitigation measures need to be improved.

From the advanced physical modeling point of view, generally, catastrophic geophysical mass flows such as avalanches (Pudasaini and Hutter, 2007), debris flows (Iverson, 1997), landslides (Legros, 2002) or submarine avalanches (Hampton and others, 1996) are characterized by the flow of a mixture of liquid and solid particles down a slope. Based on the Mohr-Coulomb frictional rheology, Savage and Hutter (1989) developed a depth-averaged continuum mechanical model to describe the flow of granular material down a rough incline (Savage and Hutter, 1989, 1991; Greve and Hutter, 1993; Tai and others, 2002; Pudasaini and Hutter, 2003, 2007). Later, this model was extended geometrically to two and three dimensions (Gray, 2001; Pudasaini and Hutter, 2003). The Coulomb mixture models of Iverson (1997) and Iverson and Denlinger (2001) and their extension by Pudasaini and others (2005) allow basal pore fluid pressure to evolve and include viscous effects. Nevertheless, these are only quasi-two-phase or virtually single-phase debris bulk models, as they do not include the differences between the fluid and solid velocities. The solid and fluid phase velocities may deviate substantially from each other in real debris flows affecting the whole flow mechanics. Depending on the material involved and the flow configuration, several other physical mechanisms must be introduced in order to properly model any two-phase mass flows (Pudasaini, 2012). Pitman and Le (2005) developed a two-fluid model that includes simple drag force to describe flows as a mixture of the solid particles and the fluid. Nevertheless, they neglect the viscous fluid effects.

During the flow, one phase (e.g. solid) may accelerate relative to another phase (e.g. fluid), thus inducing virtual mass. The quantity and concentration gradient of the solid particles influence the flow considerably, and can enhance or diminish viscous effects. Depending on the amount of grains and flow situation, the drag force should combine the solid- and fluid-like contributions and also linear (laminartype) and quadratic (turbulent-type) drags. To take into account these important aspects of a two-phase mass flow, Pudasaini (2012) developed a generalized two-phase mass flow model. This model unifies existing avalanche and debris flow theories. It covers both the single-phase and two-phase scenarios and includes many essential and observable physical phenomena. In this model, the solid phase stress is described by Mohr-Coulomb plasticity, while the fluid stress is modeled as a non-Newtonian viscous stress that is enhanced by the solid-volume-fraction gradient. A generalized interfacial momentum transfer includes viscous drag, buoyancy and virtual mass forces, and a new generalized drag force is introduced to cover both solidlike and fluid-like drags. The virtual mass force alters flow dynamics by increasing the kinetic energy of the fluid. Newtonian viscous stress substantially reduces motion and deformation, whereas non-Newtonian viscous stress may change the overall flow dynamics. Strong couplings between solid and fluid momentum transfer are another important aspect of the general two-phase model (Pudasaini, 2012, 2014). The model has further been extended and applied to simulate rock-ice avalanches with dynamic strength weakening and process transformations (Pudasaini and Krautblatter, 2014).

Previous studies on submarine landslides and tsunamis have mainly been based on impacts by non-deformable landslides (solid blocks), or at most single-phase landslides in which the waves are mainly studied with pressure-driven ideal fluids, so no viscous and frictional effects were included (Walder and others, 2003; Viroulet and others, 2013). Nevertheless, for a real two-phase solid-fluid mixture flow impacting a reservoir, viscous and drag forces play an important role in the dynamic description (Pudasaini, 2012, 2014). Here we fundamentally advance the modeling of submarine landslides, particle transport and tsunamis by considering (i) deformable and (ii) two-phase debris, (iii) in a fully-coupled solid-fluid mixture frictional and viscous model with (iv) 3-D landslide fluid body interactions, and (v) a unified and efficient simulation strategy featuring a single framework for the landslide and fluid body, impact and subsequent dynamics of landslide, debris flow, turbidity currents and tsunami. A detailed analysis of a geometrically two-dimensional (2-D), two-phase subaerial debris flow impacting a 2-D reservoir, tsunami generation and propagation and submarine landslides was presented by Pudasaini (2014) with 2-D simulation results. Here the subject is further advanced by primarily focusing on geometrically 3-D aspects of such complex two-phase flows and the related impulsive water waves (Kafle, 2014). The simultaneous dynamics of the two-phase, geometrically 3-D subaerial debris flow, the resulting tsunami generation and propagation upon debris impact at a fluid reservoir or a lake, 
the subsequent submarine debris flow, and the analysis of the wave generation, amplification, propagation and their complex interactions are studied here by applying a generalized two-phase debris flow model (Pudasaini, 2012). Simulations are performed with a high-resolution shock-capturing numerical scheme (Nessyahu and Tadmor, 1990; Tai and others, 2002; Pudasaini and Hutter, 2007). We also present scaling analyses for submergence times for non-deformable bulk and deformable two-phase debris motions. It appears that these two submergence times differ substantially. The findings contribute significantly to our understanding of mixing and separation between phases, generation and propagation of special solid and fluid structures, and phase transitions during the flow process (Kafle, 2014; Pudasaini, 2014).

\section{MODEL EQUATIONS}

In the two-phase debris mixture, the phases are characterized by different material properties. The fluid phase is characterized by its material density $\rho_{\mathrm{f}}$, viscosity $\eta_{\mathrm{f}}$ and isotropic stress distribution; whereas the solid phase is characterized by its material density $\rho_{\mathrm{s}}$, internal friction angle $\phi$, the basal friction angle $\delta$, an anisotropic stress distribution, and the lateral earth pressure coefficient, $K$. Here the subscripts $s$ and $f$ stand for the solid and the fluid phases respectively. Let depth-averaged velocity components for fluid $\mathbf{u}_{\mathrm{f}}=\left(u_{\mathrm{f}}, v_{\mathrm{f}}\right)$ and for solid $\mathbf{u}_{\mathrm{s}}=\left(u_{\mathrm{s}}, v_{\mathrm{s}}\right)$ in the downslope $(x)$ and the cross-slope $(y)$ directions, respectively, the flow depth $h$ and the solid-volume fraction $\alpha_{\mathrm{s}}$ (similarly the fluid volume fraction $\alpha_{\mathrm{f}}=1-\alpha_{\mathrm{s}}$ ) be computed as functions of space and time. The solid and fluid mass and momentum balance equations in the downslope and the cross-slope directions are given by (Pudasaini, 2012)

$$
\begin{gathered}
\frac{\partial}{\partial t}\left(\alpha_{\mathrm{s}} h\right)+\frac{\partial}{\partial x}\left(\alpha_{\mathrm{s}} h u_{\mathrm{s}}\right)+\frac{\partial}{\partial y}\left(\alpha_{\mathrm{s}} h v_{\mathrm{s}}\right)=0 \\
\frac{\partial}{\partial t}\left(\alpha_{\mathrm{f}} h\right)+\frac{\partial}{\partial x}\left(\alpha_{\mathrm{f}} h u_{\mathrm{f}}\right)+\frac{\partial}{\partial y}\left(\alpha_{\mathrm{f}} h v_{\mathrm{f}}\right)=0 \\
\frac{\partial}{\partial t}\left[\alpha_{\mathrm{s}} h\left(u_{\mathrm{s}}-\gamma \mathcal{C}\left(u_{\mathrm{f}}-u_{\mathrm{s}}\right)\right)\right] \\
+\frac{\partial}{\partial x}\left[\alpha_{\mathrm{s}} h\left(u_{\mathrm{s}}^{2}-\gamma \mathcal{C}\left(u_{\mathrm{f}}^{2}-u_{\mathrm{s}}^{2}\right)+\frac{\beta_{x_{\mathrm{s}}} h}{2}\right)\right] \\
+\frac{\partial}{\partial y}\left[\alpha_{\mathrm{s}} h\left(u_{\mathrm{s}} v_{\mathrm{s}}-\gamma \mathcal{C}\left(u_{\mathrm{f}} v_{\mathrm{f}}-u_{\mathrm{s}} v_{\mathrm{s}}\right)\right)\right]=h S_{x_{\mathrm{s}}} \\
\frac{\partial}{\partial t}\left[\alpha_{\mathrm{s}} h\left(v_{\mathrm{s}}-\gamma \mathcal{C}\left(v_{\mathrm{f}}-v_{\mathrm{s}}\right)\right)\right] \\
+\frac{\partial}{\partial x}\left[\alpha_{\mathrm{s}} h\left(u_{\mathrm{s}} v_{\mathrm{s}}-\gamma \mathcal{C}\left(u_{\mathrm{f}} v_{\mathrm{f}}-u_{\mathrm{s}} v_{\mathrm{s}}\right)\right)\right] \\
+\frac{\partial}{\partial y}\left[\alpha_{\mathrm{s}} h\left(v_{\mathrm{s}}^{2}-\gamma \mathcal{C}\left(v_{\mathrm{f}}^{2}-v_{\mathrm{s}}^{2}\right)+\frac{\beta_{y_{\mathrm{s}}} h}{2}\right)\right]=h S_{y_{\mathrm{s}}}
\end{gathered}
$$

$$
\begin{aligned}
\frac{\partial}{\partial t}\left[\alpha_{\mathrm{f}} h\right. & \left.\left(u_{\mathrm{f}}+\frac{\alpha_{\mathrm{s}}}{\alpha_{\mathrm{f}}} \mathcal{C}\left(u_{\mathrm{f}}-u_{\mathrm{s}}\right)\right)\right] \\
+ & \frac{\partial}{\partial x}\left[\alpha_{\mathrm{f}} h\left(u_{\mathrm{f}}^{2}+\frac{\alpha_{\mathrm{s}}}{\alpha_{\mathrm{f}}} \mathcal{C}\left(u_{\mathrm{f}}^{2}-u_{\mathrm{s}}^{2}\right)+\frac{\beta_{x_{\mathrm{f}}} h}{2}\right)\right] \\
+ & \frac{\partial}{\partial y}\left[\alpha_{\mathrm{f}} h\left(u_{\mathrm{f}} v_{\mathrm{f}}+\frac{\alpha_{\mathrm{s}}}{\alpha_{\mathrm{f}}} \mathcal{C}\left(u_{\mathrm{f}} v_{\mathrm{f}}-u_{\mathrm{s}} v_{\mathrm{s}}\right)\right)\right]=h S_{x_{\mathrm{f}}}
\end{aligned}
$$

$$
\begin{aligned}
& \frac{\partial}{\partial t}\left[\alpha_{\mathrm{f}} h\left(v_{\mathrm{f}}+\frac{\alpha_{\mathrm{s}}}{\alpha_{\mathrm{f}}} \mathcal{C}\left(v_{\mathrm{f}}-v_{\mathrm{s}}\right)\right)\right] \\
& \quad+\frac{\partial}{\partial x}\left[\alpha_{\mathrm{f}} h\left(u_{\mathrm{f}} v_{\mathrm{f}}+\frac{\alpha_{\mathrm{s}}}{\alpha_{\mathrm{f}}} \mathcal{C}\left(u_{\mathrm{f}} v_{\mathrm{f}}-u_{\mathrm{s}} v_{\mathrm{s}}\right)\right)\right] \\
& \quad+\frac{\partial}{\partial y}\left[\alpha_{\mathrm{f}} h\left(v_{\mathrm{f}}^{2}+\frac{\alpha_{\mathrm{s}}}{\alpha_{\mathrm{f}}} \mathcal{C}\left(v_{\mathrm{f}}^{2}-v_{\mathrm{s}}^{2}\right)+\frac{\beta_{y_{\mathrm{f}}} h}{2}\right)\right]=h S_{y_{\mathrm{f}}}
\end{aligned}
$$

in which

$$
\begin{aligned}
& \beta_{x_{\mathrm{s}}}=\varepsilon K_{x} p_{b_{\mathrm{s}}}, \beta_{y_{\mathrm{s}}}=\varepsilon K_{y} p_{b_{\mathrm{s}}} \\
& \beta_{x_{\mathrm{f}}}=\beta_{y_{\mathrm{f}}}=\varepsilon p_{b_{\mathrm{f}}}, p_{b_{\mathrm{f}}}=-g^{z}, p_{b_{\mathrm{s}}}=(1-\gamma) p_{b_{\mathrm{f}}} .
\end{aligned}
$$

Equations (1) and (2) are the depth-averaged mass balances for solid and fluid phases respectively, and Eqns (3-6) are the depth-averaged momentum balances for solid (Eqns (3) and (4)) and fluid (Eqns (5) and (6)) in the $x$ - and $y$-directions respectively. The source terms are (Pudasaini, 2012)

$$
\begin{aligned}
& S_{x_{\mathrm{s}}}=\alpha_{\mathrm{s}}\left[g^{x}-p_{b_{\mathrm{s}}}\left(\frac{u_{\mathrm{s}}}{\left|\mathbf{u}_{\mathrm{s}}\right|} \tan \delta+\varepsilon \frac{\partial b}{\partial x}\right)\right] \\
& -\varepsilon \alpha_{\mathrm{s}} \gamma p_{b_{\mathrm{f}}}\left[\frac{\partial h}{\partial x}+\frac{\partial b}{\partial x}\right]+C_{\mathrm{DG}}\left(u_{\mathrm{f}}-u_{\mathrm{s}}\right)\left|\mathbf{u}_{\mathrm{f}}-\mathbf{u}_{\mathrm{s}}\right|^{J-1}, \\
& S_{y_{\mathrm{s}}}=\alpha_{\mathrm{s}}\left[g^{y}-p_{b_{\mathrm{s}}}\left(\frac{v_{\mathrm{s}}}{\left|\mathbf{u}_{\mathrm{s}}\right|} \tan \delta+\varepsilon \frac{\partial b}{\partial y}\right)\right] \\
& -\varepsilon \alpha_{\mathrm{s}} \gamma p_{b_{\mathrm{f}}}\left[\frac{\partial h}{\partial y}+\frac{\partial b}{\partial y}\right]+C_{\mathrm{DG}}\left(v_{\mathrm{f}}-v_{\mathrm{s}}\right)\left|\mathbf{u}_{\mathrm{f}}-\mathbf{u}_{\mathrm{s}}\right|^{\nu-1}, \\
& S_{x_{\mathrm{f}}}=\alpha_{\mathrm{f}}\left[g^{x}-\varepsilon\left[\frac{1}{2} p_{b_{\mathrm{f}}} \frac{h}{\alpha_{\mathrm{f}}} \frac{\partial \alpha_{\mathrm{s}}}{\partial x}+p_{b_{\mathrm{f}}} \frac{\partial b}{\partial x}\right.\right. \\
& -\frac{1}{\alpha_{\mathrm{f}} N_{R}}\left\{2 \frac{\partial^{2} u_{\mathrm{f}}}{\partial x^{2}}+\frac{\partial^{2} v_{\mathrm{f}}}{\partial y \partial x}+\frac{\partial^{2} u_{\mathrm{f}}}{\partial y^{2}}-\frac{\chi u_{\mathrm{f}}}{\varepsilon^{2} h^{2}}\right\} \\
& +\frac{1}{\alpha_{\mathrm{f}} N_{R_{\mathcal{A}}}}\left\{2 \frac{\partial}{\partial x}\left(\frac{\partial \alpha_{\mathrm{s}}}{\partial x}\left(u_{\mathrm{f}}-u_{\mathrm{s}}\right)\right)\right. \\
& \left.+\frac{\partial}{\partial y}\left(\frac{\partial \alpha_{\mathrm{s}}}{\partial x}\left(v_{\mathrm{f}}-v_{\mathrm{s}}\right)+\frac{\partial \alpha_{\mathrm{s}}}{\partial y}\left(u_{\mathrm{f}}-u_{\mathrm{s}}\right)\right)\right\} \\
& \left.\left.-\frac{\xi \alpha_{\mathrm{s}}\left(u_{\mathrm{f}}-u_{\mathrm{s}}\right)}{\varepsilon^{2} \alpha_{\mathrm{f}} N_{R_{\mathcal{A}}} h^{2}}\right]\right]-\frac{1}{\gamma} C_{\mathrm{DG}}\left(u_{\mathrm{f}}-u_{\mathrm{s}}\right)\left|\mathbf{u}_{\mathrm{f}}-\mathbf{u}_{\mathrm{s}}\right|^{J-1}, \\
& S_{y_{\mathrm{f}}}=\alpha_{\mathrm{f}}\left[g^{y}-\varepsilon\left[\frac{1}{2} p_{b_{\mathrm{f}}} \frac{h}{\alpha_{\mathrm{f}}} \frac{\partial \alpha_{\mathrm{s}}}{\partial y}+p_{b_{\mathrm{f}}} \frac{\partial b}{\partial y}\right.\right. \\
& -\frac{1}{\alpha_{\mathrm{f}} N_{R}}\left\{2 \frac{\partial^{2} v_{\mathrm{f}}}{\partial y^{2}}+\frac{\partial^{2} u_{\mathrm{f}}}{\partial x \partial y}+\frac{\partial^{2} v_{\mathrm{f}}}{\partial x^{2}}-\frac{\chi v_{\mathrm{f}}}{\varepsilon^{2} h^{2}}\right\} \\
& +\frac{1}{\alpha_{\mathrm{f}} N_{R_{\mathcal{A}}}}\left\{2 \frac{\partial}{\partial y}\left(\frac{\partial \alpha_{\mathrm{s}}}{\partial y}\left(v_{\mathrm{f}}-v_{\mathrm{s}}\right)\right)\right. \\
& \left.+\frac{\partial}{\partial x}\left(\frac{\partial \alpha_{\mathrm{s}}}{\partial y}\left(u_{\mathrm{f}}-u_{\mathrm{s}}\right)+\frac{\partial \alpha_{\mathrm{s}}}{\partial x}\left(v_{\mathrm{f}}-v_{\mathrm{s}}\right)\right)\right\} \\
& \left.\left.-\frac{\xi \alpha_{\mathrm{s}}\left(v_{\mathrm{f}}-v_{\mathrm{s}}\right)}{\varepsilon^{2} \alpha_{\mathrm{f}} N_{R_{\mathcal{A}}} h^{2}}\right]\right]-\frac{1}{\gamma} C_{\mathrm{DG}}\left(v_{\mathrm{f}}-v_{\mathrm{s}}\right)\left|\mathbf{u}_{\mathrm{f}}-\mathbf{u}_{\mathrm{s}}\right|^{J-1},
\end{aligned}
$$

where

$$
\begin{aligned}
C_{\mathrm{DG}} & =\frac{\alpha_{\mathrm{s}} \alpha_{\mathrm{f}}(1-\gamma)}{\left[\varepsilon \mathcal{U}_{\mathrm{T}}\left\{\mathcal{P} \mathcal{F}\left(\operatorname{Re}_{\mathrm{p}}\right)+(1-\mathcal{P}) \mathcal{G}\left(\operatorname{Re}_{\mathrm{p}}\right)\right\}\right]^{\prime}}, \gamma=\frac{\rho_{\mathrm{f}}}{\rho_{\mathrm{s}}}, \\
\mathcal{F} & =\frac{\gamma}{180}\left(\frac{\alpha_{\mathrm{f}}}{\alpha_{\mathrm{s}}}\right)^{3} \operatorname{Re}_{\mathrm{p}}, \mathcal{G}=\alpha_{\mathrm{f}}^{M\left(R e_{\mathrm{p}}\right)-1}, \operatorname{Re}_{\mathrm{p}}=\frac{\rho_{\mathrm{f}} d \mathcal{U}_{\mathrm{T}}}{\eta_{\mathrm{f}}}, \\
N_{R} & =\frac{\sqrt{g L} H \rho_{\mathrm{f}}}{\alpha_{\mathrm{f}} \eta_{\mathrm{f}}}, N_{R_{\mathcal{A}}}=\frac{\sqrt{g L} H \rho_{\mathrm{f}}}{\mathcal{A} \eta_{\mathrm{f}}} .
\end{aligned}
$$

In the above equations, $x, y$ and $z$ are coordinates along the flow directions, and $g^{x}, g^{y}$ and $g^{z}$ are the components of gravitational acceleration. $L$ and $H$ are the typical length and 
depth of the flow, $\varepsilon=H / L$ is the aspect ratio and $\mu=\tan \delta$ is the basal friction coefficient. $K$ is the earth pressure coefficient, and $C_{\mathrm{DG}}$ is the generalized drag coefficient. Simple linear (laminar-type, at low velocity) or quadratic (turbulent-type, at high velocity) drag is associated with $J=1$ or 2 respectively. $\mathcal{U}_{\mathrm{T}}$ is the terminal velocity of a particle and $\mathcal{P} \in[0,1]$ is a parameter which combines the solid-like $(\mathcal{G})$ and fluid-like $(\mathcal{F})$ drag contributions to flow resistance. $p_{b_{\mathrm{f}}}$ and $p_{b_{\mathrm{s}}}$ are the effective fluid and solid pressures. $\gamma$ is the density ratio, $\mathcal{C}$ is the virtual mass coefficient (kinetic energy of the fluid phase induced by solid particles), $\eta_{\mathrm{f}}$ is the fluid viscosity, $M$ is a function of the particle Reynolds number $\left(R_{\mathrm{e}_{\mathrm{p}}}\right), \chi$ includes vertical shearing of fluid velocity, and $\xi$ takes into account different distributions of $\alpha_{\mathrm{s}}$. $\mathcal{A}$ is the mobility of the fluid at the interface, and $N_{R}$ and $N_{R_{\mathcal{A}}}$, respectively, are the quasi-Reynolds number and mobilityReynolds number associated with the classical Newtonian and enhanced non-Newtonian fluid viscous stresses. Slope topography is represented by $b=b(x, y)$.

The scaling analysis provides important information for the problem under consideration. With regard to tsunamis generated by landslide impacts, the experimental results are often used to validate the predictions of the scaling analysis (Slingerland and Voight, 1979; Walder and others, 2003; Viroulet and others, 2013). The model equations (1-6) are presented in non-dimensional form so as to identify physically relevant and dominant terms (Pudasaini, 2012). A typical speed for avalanches and landslides is the freefall velocity and for water the shallow-water velocity (Pudasaini and Hutter, 2007). This means that the characteristic time $(\sqrt{L / g})$ and velocity $(\sqrt{g L})$ in landslide scales with typical landslide length $(L)$ whereas the length scale in shallow water flow is the typical shallow water height $(H)$ resulting in the shallow water time $(\sqrt{H / g})$ and velocity $(\sqrt{g H})$ that differ substantially from those for avalanches and landslides. Non-dimensionalization in Eqns (1-6) is based on this widely used rapid landslide and debris-flow scaling.

\section{SIMULATING TWO-PHASE SUBMARINE DEBRIS FLOW AND TSUNAMI}

Real two-phase debris mass flows, both subaerial and submarine, were simulated by Pudasaini $(2012,2014)$ for the first time for the explicit evolution of the solid and fluid phases as the debris mass collapses and slides down the slope. Particularly, Pudasaini and Miller (2012) and Pudasaini (2014) simulated geometrically 2-D flows in which two-phase subaerial debris flows hit a still reservoir, producing tsunamis upon impact and generating submarine debris slides along the bed of the reservoir. Recently, for idealized geometry, Kafle (2014) has advanced further by simulating two-phase and 3-D subaerial flows impacting a fluid reservoir and has simulated some observable natural phenomena for the first time by using the real two-phase debris-flow model (Pudasaini, 2012). Here we present some novel results for 3-D tsunami generation, amplification, propagation, submarine debris flows and the complex interactions between the tsunami and submarine debris waves with detailed analysis.

\section{Numerical method}

The model equations (1-6) are a set of well-structured, nonlinear hyperbolic-parabolic partial differential equations in conservative form with complex source terms (Pudasaini, 2012). These model equations are used to compute the debris depth $h$, solid volume fraction $\alpha_{\mathrm{s}}$, velocity components for solid $\left(u_{\mathrm{s}}, v_{\mathrm{s}}\right)$, and for fluid $\left(u_{\mathrm{f}}, v_{\mathrm{f}}\right)$ in $x$ - and $y$-directions, respectively, as functions of space and time. The model equations are solved in conservative variables $\mathbf{W}=\left(h_{\mathrm{s}}, h_{\mathrm{f}}, m_{\mathrm{s}}, m_{\mathrm{f}}\right)^{t}$, where $h_{\mathrm{s}}=\alpha_{\mathrm{s}} h, h_{\mathrm{f}}=\alpha_{\mathrm{f}} h$ are the solid and fluid contributions to the debris, or the flow height; and $m_{\mathrm{s}}=\alpha_{\mathrm{s}} h u_{\mathrm{s}}, m_{\mathrm{f}}=\alpha_{\mathrm{f}} h u_{\mathrm{f}}$, are the solid and fluid momenta. This facilitates numerical integration even when shocks are formed in the field variables (Pudasaini, 2012). The highresolution shock-capturing Total Variation Diminishing Non-Oscillatory Central (TVD-NOC) scheme has been implemented (Tai and others, 2002; Pudasaini and Hutter, 2007; Domnik and others, 2013; Kafle, 2014; Kattel, 2014). Advantages of the applied innovative and unified simulation technique for real two-phase debris flows and the corresponding computational strategy are explained in Pudasaini (2014) for 2-D simulations. This technique has been extended in Kafle (2014) and Kattel (2014) for basic 3-D subaerial flows, submarine debris flows and subsequent tsunamis.

\section{Simulation set-up and parameters}

For simulation, we consider a 3-D and two-phase subaerial debris flow that hits a fluid reservoir (Fig. 1). The upper part of the channel is inclined downwards to the right $\left(\zeta=45^{\circ}\right)$ and is flat in the lateral direction. The left end of the reservoir meets an inclined surface (plane) at $x=160 \mathrm{~m}$, where the initial water height is zero. The inclined surface continues to $x=200 \mathrm{~m}$, where the water height $h=40 \mathrm{~m}$. To the right of $x=200 \mathrm{~m}$, the bed of the reservoir is horizontal and the initial fluid height remains constant, i.e. $h=40 \mathrm{~m}$ from $x=200 \mathrm{~m}$ to $x=350 \mathrm{~m}$. The initial debris mass in the upper part of the slope is uniformly distributed as a homogeneous mixture of $65 \%$ solid and $35 \%$ fluid. Similarly, initially the quiescent reservoir consists of $2 \%$ solid and $98 \%$ fluid. The other parameter values chosen for simulation are $\phi=35^{\circ}$, $\delta=15^{\circ}, \rho_{\mathrm{f}}=1100 \mathrm{~kg} \mathrm{~m}^{-3}, \quad \rho_{\mathrm{s}}=2900 \mathrm{~kg} \mathrm{~m}^{-3}, \quad N_{R}=30000$, $N_{R_{\mathcal{A}}}=1000, \operatorname{Re}_{\mathrm{p}}=1, \mathcal{U}_{\mathrm{T}}=5.0 \mathrm{~m} \mathrm{~s}^{-1}, \mathcal{P}=0.75, J=1$ (we consider only linear drag), $\chi=0, \xi=0, \mathcal{C}=0.5$. As discussed in Pudasaini $(2012,2014)$, Pudasaini and Miller (2012) and Pudasaini and Krautblatter (2014), these parameter selections are based on the physics of the two-phase subaerial and submarine mass flows and associated tsunami generation and propagation.

\section{Simulation results and discussion}

The area in the vicinity of the wave generation by landslide impact is called the splash zone, where the landslide motion is coupled with water waves as long as the landslide motion continues (Walder and others, 2003). Fritz and others (2001) experimentally investigated the splash induced by granular landslides. The splash zone hydrodynamics is explained theoretically by Watts and Walder (2003) for the singlephase landslide impact and by Pudasaini (2014) for twophase debris impact on a particle-laden reservoir for 2-D flows. Here, including other aspects, such as near and far fields, we advance further by investigating a complex 3-D splash zone dynamics generated by a real two-phase debris mass flow as it impacts a particle-laden fluid reservoir. The simulations are presented for three different initial debris locations: at the top and middle of the inclined subaerial slope and on the left shoreline. In general, our simulations 

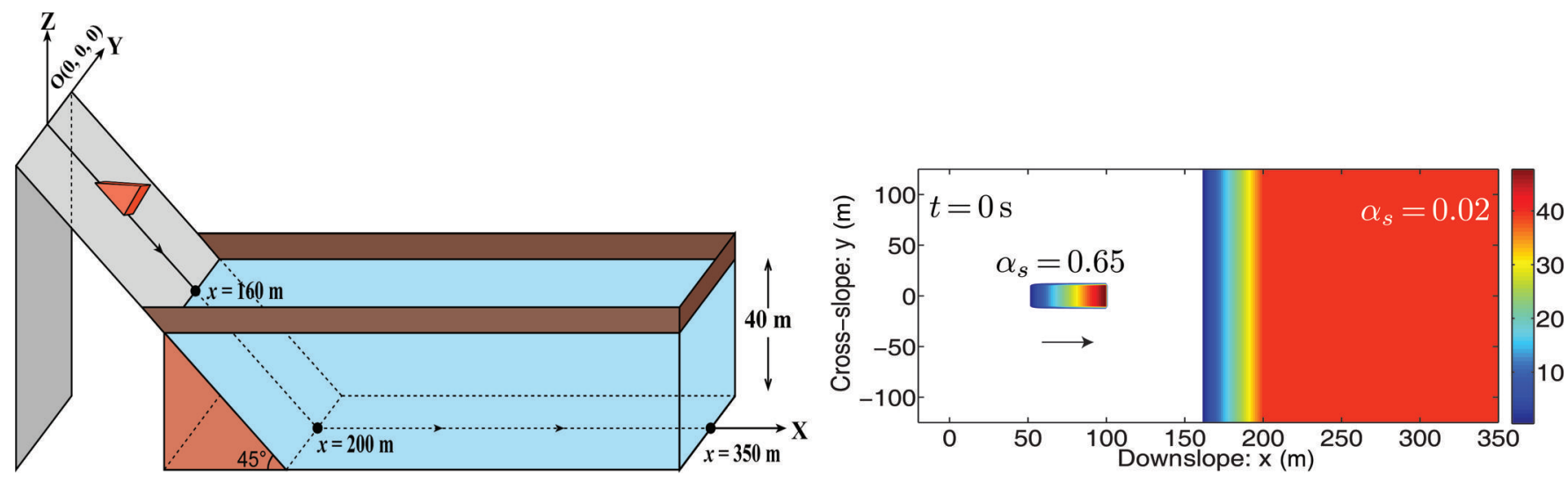

Fig. 1. Left: A sketch of the initial configuration of a debris mass on an inclined slab with a fluid reservoir downslope. As the debris moves down the slope and hits the fluid reservoir the tsunami waves will be generated. Right: Initially at $t=0 \mathrm{~s}$, the debris is in the form of a laterally spanned triangular wedge $(50 \leq x \leq 100 ;-12 \leq y \leq 12)$, which is shown in bird's-eye perspective for simplicity. Initially, debris consists of $65 \%$ solid $\left(\alpha_{s}=0.65\right)$ whereas the reservoir initially contains $2 \%$ solid particles $\left(\alpha_{\mathrm{s}}=0.02\right)$. The colour map provides necessary information about the flow depth and the mass distribution. Arrow indicates main flow (downslope) direction.

can be used to predict the splash, near-field and far-field wave dynamics for 3-D slopes whereas experiments and dimensional analysis are usually focused on some of these aspects for relatively simple geometries (Slingerland and Voight, 1979; Fritz and others, 2001; Walder and others, 2003; Viroulet and others, 2013).

\section{Initial debris in the middle of the subaerial slope}

Simulation results for the evolution of the subaerial and submarine debris flows, and the tsunami generation by the debris impact and the subsequent complex fluid waves are presented here. Figure 2 presents some basic results in terms of the total debris depth (the sum of the solid and the fluid heights) along with the evolution of the solid phase, the penetration of the debris into the reservoir, the motion of the submarine debris flows, and the complex wave interactions. At $t=1 \mathrm{~s}$ (left panel a), the debris mass is only stretching and moving on the inclined plane, mainly in the downslope direction, but also in the cross-slope direction. At this stage, as the mass has been continuously spread on the inclined plane, the subaerial debris height has been substantially decreased.

The interesting point to observe here is the special evolution of the (subaerial) total debris: the debris height increases quickly from the front to the main body of the debris mass, whose maximum height appears to be closer to the frontal part of the debris than to the middle part (Kafle, 2014). Then the debris height decreases to form a relatively long tail. The debris hits the center of the left coast of the reservoir to generate a tsunami just after $t=2 \mathrm{~s}$ (left panel b). As the debris hits the reservoir, the debris mass slides down the bathymetric slope as a submarine debris flow (Pudasaini, 2014) and the tsunami propagates. As the debris continues to hit the reservoir with higher momentum $(t=4 \mathrm{~s}$, left panel d), the tsunami is amplified in the vicinity of the impact $(t=5 \mathrm{~s}$, left panel e) and more and more fluid mass from the left of the reservoir is strongly pushed forward (right) and laterally. This produces a strong 3-D hydrodynamic impact vacuum (Pudasaini, 2014), or crater (Fritz and others, 2003), which grows and persists for some time. For $t>2 \mathrm{~s}$, three complex flows occur simultaneously: (i) a subaerial debris flow in the upstream region, (ii) submarine debris flow in the downstream region and in the reservoir, and (iii) a super tsunami on the surface of the reservoir (for $t=5 \mathrm{~s}$ to $t=7 \mathrm{~s}$ the surface tsunami is on the order of $25-30 \mathrm{~m}$ high in the vicinity of the impact). The height of the water surface has been substantially increased due to the tsunami and the pushing of the water to the right (up to slightly more than $x=200 \mathrm{~m}$ ), resulting in a maximum fluid height of $\sim 48 \mathrm{~m}$ around $x=200 \mathrm{~m}$. From slightly more than $x=200 \mathrm{~m}$ to $x=300 \mathrm{~m}$, the height of the water surface decreased to $\sim 35 \mathrm{~m}$. However, from around $x=300 \mathrm{~m}$ to $350 \mathrm{~m}$, the height of the water surface remains unchanged $(40 \mathrm{~m})$. Amplified 3-D tsunami waves are clearly observed at $t=3 \mathrm{~s}$ to $t=7 \mathrm{~s}$ (left panels $\mathrm{c}-\mathrm{g}$ ). The tsunami propagates in all three directions, as seen from the wavy color maps. At about $t=7 \mathrm{~s}$ (left panel g), the total debris mass has almost submerged in the fluid of the reservoir, generating strong symmetrical lateral waves.

Qualitatively, the total and the fluid-only geometric evolutions are similar (Kafle, 2014). This is because, with respect to the amount of the fluid in the reservoir, the fluid component (volume fraction) dominates the solid, so the total and the fluid phase evolutions are similar. However, the dynamics of the solid phase is completely different, mainly in the reservoir. Thus, the flow behavior of the solidonly is presented in Figure $2 \mathrm{~B}$ as extracted from the total debris from Figure 2A. By analyzing the evolution of the solid phase, the dynamics of the submarine debris flows and turbidity currents can be adequately described (Pudasaini, 2014). Thus, with respect to Figure $2 B$, it is important to explain the overall dynamics, shape evolution and the propagation of the solid phase. There are several geometrically interesting and dynamically important features in Figure $2 \mathrm{~B}$. As the mass is released, the front is rarefied and accelerating mainly due to the pressure associated with the depth, and also gravity. But, due to the support of the mass from the front and the material frictions, the rear part takes more time to disperse and to slide downslope. Although, after the mass collapses, the front propagates downslope, from time $t=1 \mathrm{~s}$ (right panel a) to $t=3 \mathrm{~s}$ (right panel $\mathrm{c}$ ), the position of the relative maximum height moves a little upslope. However, this does not mean that the absolute and the initial maximum propagate upslope. At time $t=4 \mathrm{~s}$ (right panel $\mathrm{d}$ ), the maximum height position moves downslope, because around this time the initial solid mass 
A Total height/tsunami
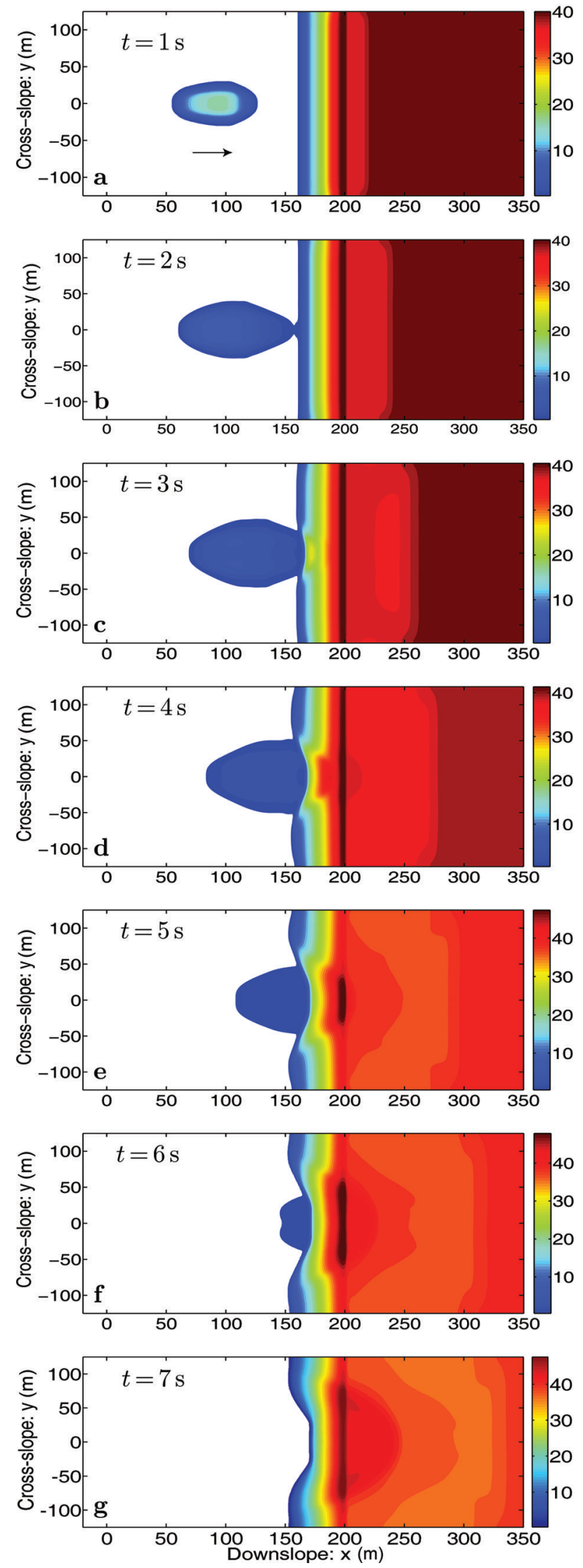

\section{B Solid height/submarine flows}
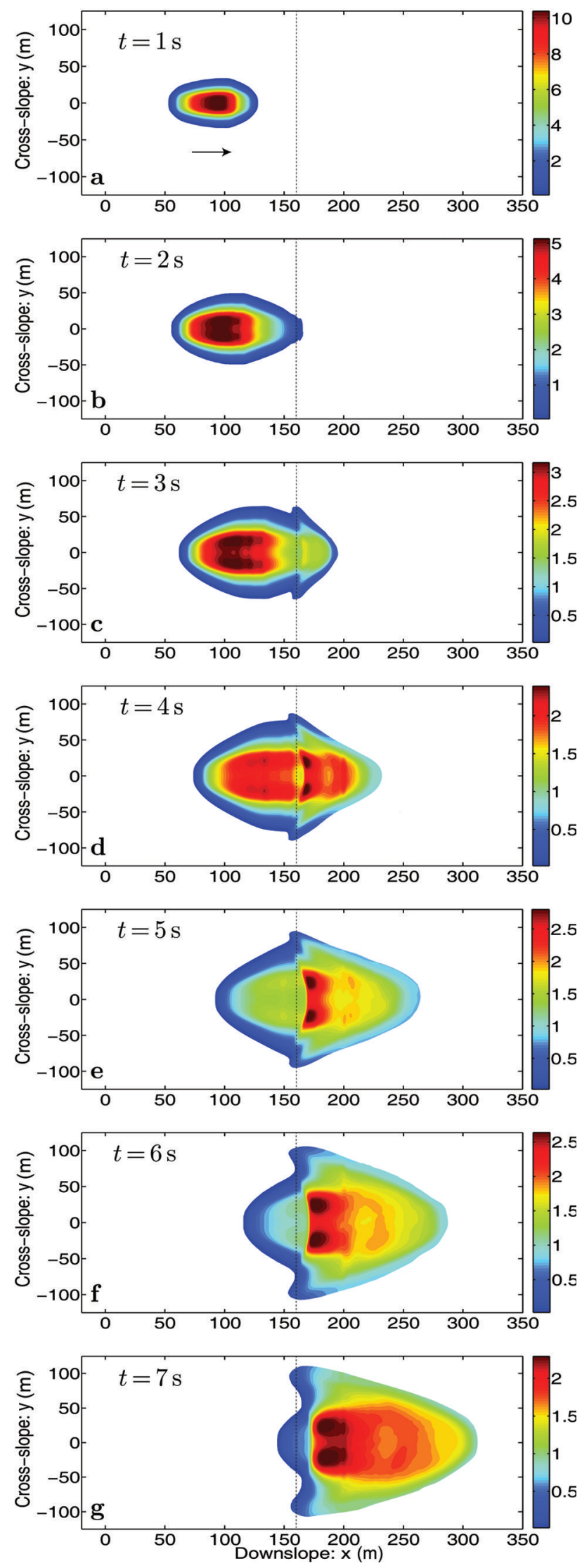

Fig. 2. A: Total height of the debris mass when initially the reservoir contains $2 \%$ solid grains, while the initial subaerial debris consists of $65 \%$ solid grains and 35\% fluid. As time elapses, the formation, amplification, propagation, reflection and intersection of coupled 3-D tsunami waves are observed as subaerial two-phase debris mass impacts the quiescent water reservoir. B: Evolution of the solid phase only as extracted from the total debris from A. As soon as mass is released, the front is rarefied and accelerates. From $t=3 \mathrm{~s}$ to $t=7 \mathrm{~s}$, the solid mass forms a very special forward-propagating cone-shaped solid wave which is similar to a laterally wide and curved mushroom hat or which is also very close to a bell-shaped wave. Arrow indicates main flow (downslope) direction. 
in the rear part of the pile has been sheared and moved downslope. However, at $t=3 \mathrm{~s}$ (right panel c), due to the impact of the subaerial (solid) mass on the reservoir, the solid mass has also been sheared in the cross-slope direction, resulting in the cross-wise elongation of the solid mass from the front to the middle portion $(t=4 \mathrm{~s}$, right panel $d$ ), where the impact has influenced the dynamics. Due to the impact, the lateral (along $y$-direction) spreading of the solid mass has increased, at time $t=4 \mathrm{~s}$ (right panel d) to $t=7 \mathrm{~s}$ (right panel g). Two longitudinally oriented local relative solid maxima, symmetric on either side of the central line $(y=0)$ of the channel, are seen from time $t=4 \mathrm{~s}$ (right panel $\mathrm{d}$ ) to $t=7 \mathrm{~s}$ (right panel $\mathrm{g}$ ). The maximum height of the solid phase decreases from $t=1 \mathrm{~s}$ (right panel a) to $t=3 \mathrm{~s}$ (right panel c) by its spreading. Surprisingly, it increases after $t=4 \mathrm{~s}$ (right panel $\mathrm{d}$ ), because now the solid deposition process has begun. Again it decreases from $t=6 \mathrm{~s}$ (right panel f) onward due to the diffusion of the deposited mass and the progressive decrease of momentum of the approaching mass from upslope.

Another important aspect is the geometrical shape change of the sliding mass, mainly its deformation. This is particularly interesting as soon as the debris mass hits the fluid reservoir at time $t=3 \mathrm{~s}$ (right panel c). Due to the impact on the fluid reservoir, from $t=3 \mathrm{~s}$ (right panel $\mathrm{c}$ ) to $t=7 \mathrm{~s}$ (right panel g), this forms a forward-propagating cone-shaped solid wave. This is due to the fact that, before the debris impacts on the reservoir, the solid phase characteristically was elongated in the downslope direction. As soon as the subaerial mass impacted the reservoir, the solid mass was also pushed or sheared in the lateral $(y)$ direction. However, since the debris is plunged into the reservoir, such a forward-facing, propagating and expanding complex conical wave develops and evolves as the debris mass continues to impact the reservoir and the debris slides along the basal surface of the reservoir. Figure 2 (right) also shows the propagation of the turbidity current and diffusing solid waves in the front and the lateral margins. Interestingly, strong depositional shock waves are developed in the vicinity of $x=200 \mathrm{~m}$. For $t>2 \mathrm{~s}$, the tooth-formed solid structures develop in the subaerial region while double depositional lobes develop in the submarine region. Such structures are attributed to the drag, which is maximum at the flow center due to maximum velocity.

\section{Initial debris at the top of the subaerial slope}

Next, we analyze in detail the effects of subaerial position of the initial debris mass on the splash, tsunami generation, and submarine debris mass movements. Figure 3 describes some basic results as in Figure 2 but now the initial debris position is farther upslope and extends from $x=-10 \mathrm{~m}$ to $40 \mathrm{~m}$. The debris hits the center of the left shore of the reservoir to generate a tsunami only after $t=4 \mathrm{~s}$ (left panel $\mathrm{d}$ ). Due to the longer subaerial travel distance, here the debris mass is laterally more spread both on the subaerial and submarine parts of the incline. Although the mass accelerates faster than in Figure 2, due to this spreading the tsunami amplifications are similar. Notably, both the impact time and the full submergence time are larger here than in Figure 2.

In Figure 2B, the solid mass forms a very special newly observed forward-propagating cone-shaped solid wave from $t=3 \mathrm{~s}$, whereas in Figure 3B such structures are formed only from $t=4 \mathrm{~s}$ and the subsequent solid structures are fundamentally different than in Figure 2. In Figure 3B, solid mass is much more elongated in the cross-slope direction than in Figure 2B. In Figure 2B, maximum solid height has decreased from $10 \mathrm{~m}$ at $t=1 \mathrm{~s}$ to $2.3 \mathrm{~m}$ at $t=4 \mathrm{~s}$, increased to $2.5 \mathrm{~m}$ at $t=5 \mathrm{~s}, 6 \mathrm{~s}$ and again decreased to $2.2 \mathrm{~m}$ at $t=7 \mathrm{~s}$. Due to the greater lateral spreading of the debris during the subaerial and submarine motions, in Figure 3B, maximum solid height has decreased from $10 \mathrm{~m}$ at $t=1 \mathrm{~s}$ to $1.7 \mathrm{~m}$ at $t=5 \mathrm{~s}$, increased to about $2 \mathrm{~m}$ at $t=6 \mathrm{~s}$ and again decreased to $<2 \mathrm{~m}$ at $t=7 \mathrm{~s}$. The consequence of this spreading can be clearly observed in the front positions: the submarine front position in Figure 2 is farther than $x=300 \mathrm{~m}$ whereas the front position of the submarine solid mass in Figure 3 is close to $x=250 \mathrm{~m}$. The same is true for their rear positions: the submarine rear in Figure 2 is close to $x=150 \mathrm{~m}$, but it is close to $x=100 \mathrm{~m}$ in Figure 3 . Furthermore, the submarine mass at $t=7 \mathrm{~s}$ in Figure 2 is largely elongated in the downslope direction with a major portion of the solid mass lying to the left of $x=200 \mathrm{~m}$ whereas the submarine mass in Figure 3 is largely sheared and elongated in the cross-slope direction, forming a type of transverse wall at around $x=200 \mathrm{~m}$.

\section{Debris initially at the shore}

Further simulations are performed with the debris front lying initially at the left shore of the reservoir expanding from $x=110 \mathrm{~m}$ to $160 \mathrm{~m}$. The results are presented in Figure 4 . In this situation, the tsunami waves are generated much earlier than in the previous cases (Figs 2 and 3). The dynamics is smoother now than in the previous cases in which the landslide impacts were more pronounced. The water wave is now clearly visible even at $t=1 \mathrm{~s}$. Nevertheless, as the mass accelerates downslope the motion is mainly pressuredriven and there is little inertia at the inception of the motion, so an extensive tsunami is not created in these early stages. In the present situation, in the initial stage, much thicker debris exerts pressure on the still fluid in the reservoir. This is the main initial mechanism in generating the tsunami wave, whereas in the previous cases tsunamis were generated by strong impact of rapidly cascading relatively thin subaerial debris. The effect of this impulse mechanism is clearly seen in the semicircular forwardpropagating tsunami wave whose intensity, nevertheless, decreases as the wave propagates to the far field (to the right). Such special behaviors are observed in landslidegenerated tsunamis in the field and laboratory (Walder and others, 2003; Viroulet and others, 2013). As the debris mass pushes the reservoir fluid and accelerates downslope, highamplitude and strongly curved tsunami waves are observed along the left shoreline, creating a large trough in the center of the shore. The debris mass almost fully enters the reservoir and submerges fully already at $t<6 \mathrm{~s}$ as the longitudinal extent of the debris is substantially shorter now than in the previous cases. Then, due to the ceasing of the debris mass flow, the left coast tsunami begins to propagate upslope (backwards) to fill the previously generated debris impact vacuum (Pudasaini, 2014).

Other remarkable differences are seen in the submarine debris mass and the evolution of the solid fraction (Fig. 4B). The solid fraction reveals two main characteristics. First, the front has propagated much farther but is more diffusive now, akin to a dilute turbidity current. This can be explained physically because there is not much momentum available, and the lower kinetic energy is not able to transport a 


\section{A Total height/tsunami}
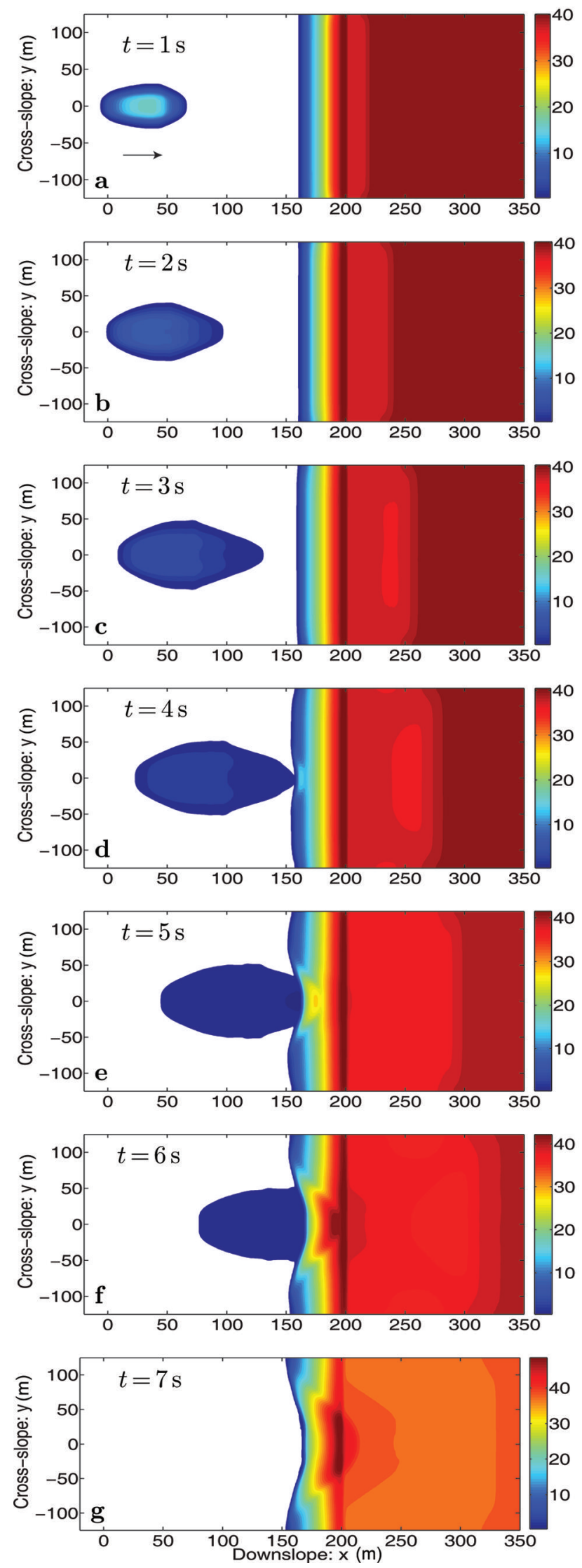

\section{B Solid height/submarine flows}
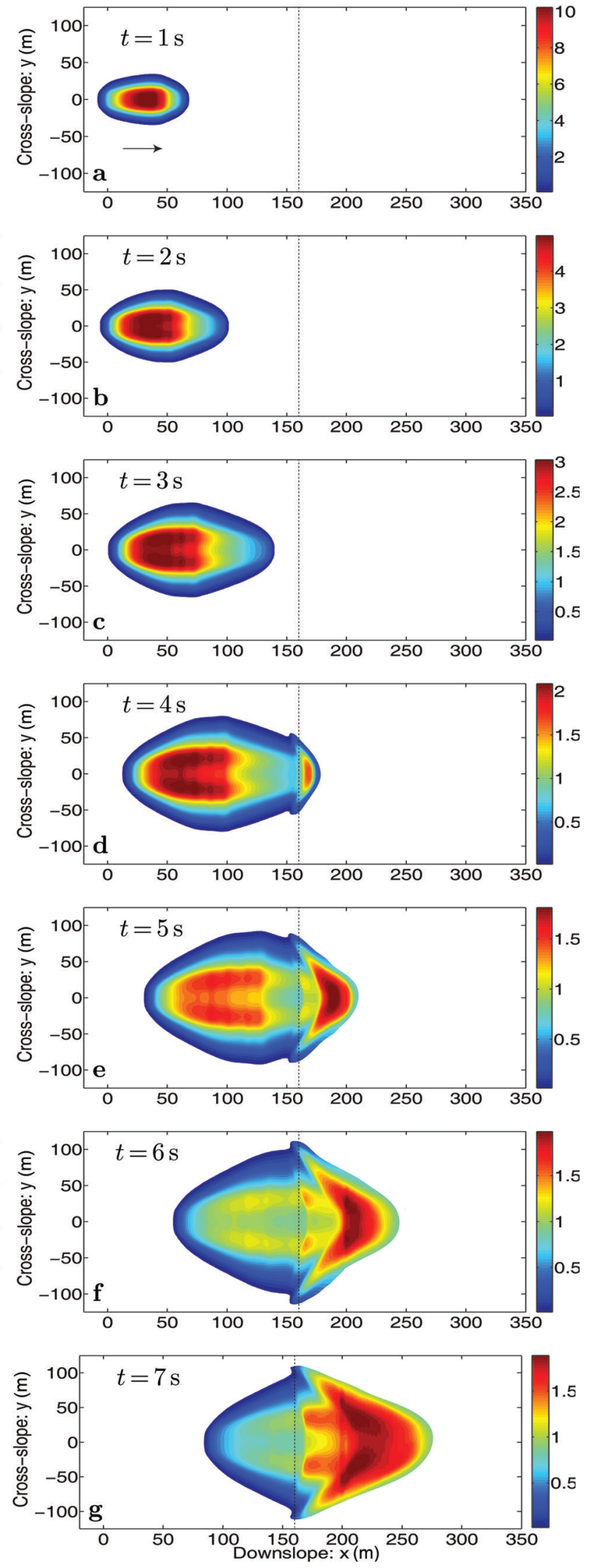

Fig. 3. A: Total height of the debris mass when initially the reservoir contains $2 \%$ solid grains, while the initial subaerial debris consists of $65 \%$ solid grains and $35 \%$ fluid positioned from $x=-10 \mathrm{~m}$ to $40 \mathrm{~m}$ (i.e. top of the slope). As time elapses, the formation, amplification, propagation, reflection and interaction of coupled 3-D tsunami waves are observed as subaerial two-phase debris mass impacts the quiescent water reservoir. B: Evolution of the solid phase only as extracted from the total debris from A. As soon as mass is released, the front is rarefied and accelerated. From $t=4 \mathrm{~s}$ to $t=7 \mathrm{~s}$, the solid mass forms a very special forward-propagating cone-shaped solid wave (or a laterally wide and curved mushroom hat, or a bell-shaped wave). Arrow indicates main flow (downslope) direction. 


\section{A Total height/tsunami}
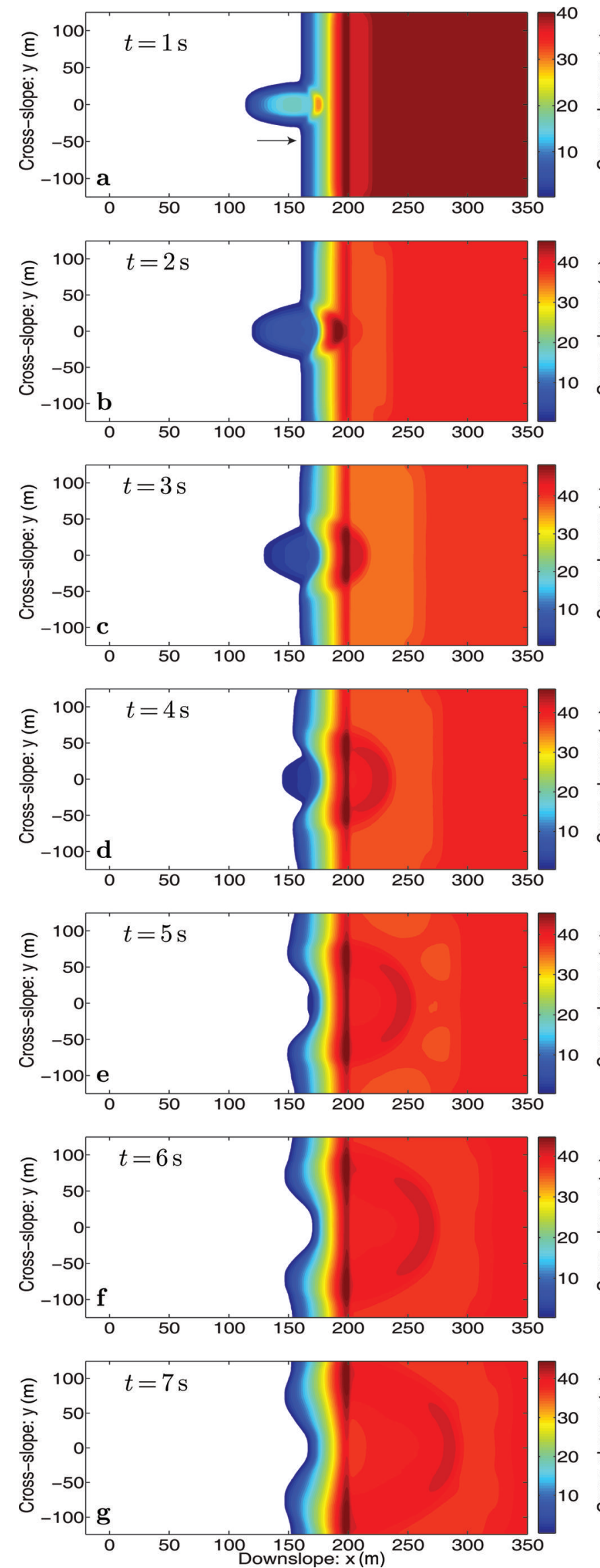

\section{B Solid height/submarine flows}
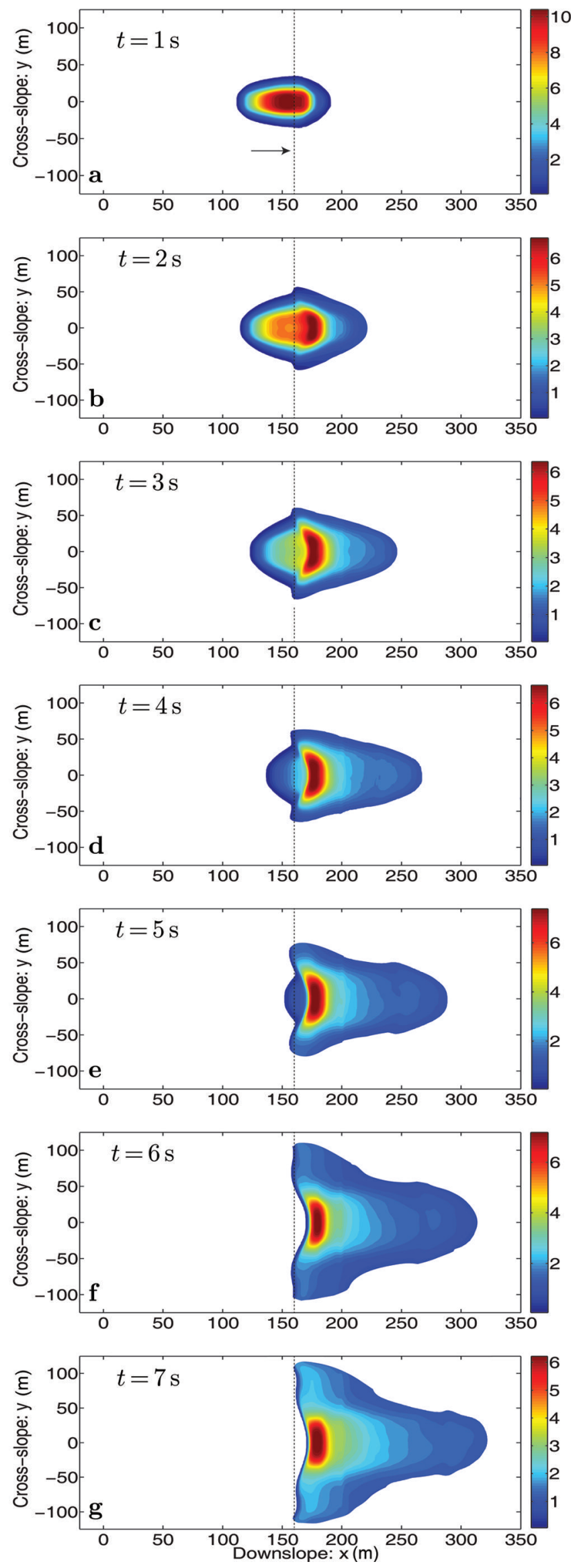

Fig. 4. A: Total height of the debris mass when initially the reservoir contains $2 \%$ solid grains and $98 \%$ fluid, while the initial subaerial debris consists of $65 \%$ solid grains and $35 \%$ fluid positioned from $x=110 \mathrm{~m}$ to $160 \mathrm{~m}$ (i.e. bottom of the slope). B: Evolution of the solid phase only as extracted from the total debris from A. Arrow indicates main flow (downslope) direction. 
substantial quantity of solid particles downslope. Moreover, due to relatively slow debris motion the drag is less, so the dilute front can move substantially farther than in the previous cases. Second, and consequently, the solid shows more and immediate depositional behavior, and the major portion of the solid material is deposited just before it reaches the flat part of the reservoir bed. Overall, the depositional pattern is smoother, but the main deposition reveals a backward-propagating shock wave from $t=2 \mathrm{~s}$ to $t=6 \mathrm{~s}$. After that, the shock diffuses to some extent. Due to the weak frontal dispersion and strong backward-propagating shock wave generated by rapid submarine mass accumulation, the maximum submarine solid height remains largely unchanged from $t=2 \mathrm{~s}$ to $t=6 \mathrm{~s}$. Furthermore, the major portion of the solid mass fraction is elongated across-slope whereas the dispersed and dilute mass is elongated in the downslope direction. These are fundamentally different characteristics than for flows initiated from the upstream subaerial positions.

These findings contribute significantly to our understanding of mixing and separation between phases, generation and propagation of special solid and fluid structures, and phase transitions during the flow process (Kafle, 2014; Pudasaini and others, 2014). By properly translating the debris-flow topography and the real field reservoir's physical settings in terms of our modeling and computational code, the magnitudes and run-ups of possible tsunamis and submarine sediment transport can be described, which can be useful for prevention and mitigation plans.

\section{SCALING LAWS}

Based on experimental data and dimensional analysis, Slingerland and Voight (1979) proposed an empirical logarithmic equation for maximum wave amplitude as a function of landslide kinetic energy and water depth. Walder and others (2003) demonstrated that the shape and height of the generated wave in the near field depend on the water depth, the volume of the slide and the duration of the submerged landslide motion. Further, based on a simple shallow-water model, Viroulet and others (2013) proposed scaling laws for maximum arrival time and wave amplitude. These laws are validated with experiments.

It is intuitively clear that the submergence scale depends upon the landslide source location and its behavior as it submerges. To show this, as in Walder and others (2003), we consider two scenarios: First, the landslide begins from far upslope (at a height $H_{\text {sa }}$ above the shoreline where sa stands for subaerial height) and impacts the water body with a higher dynamic velocity (cases I and II). Then, the landslide may decelerate in the submarine environment. The water depth in the reservoir is denoted by $H_{\mathrm{sm}}(\mathrm{sm}$ stands for submarine depth). Second (case III), the landslide's toe lies just at the shoreline (i.e. $H_{\mathrm{sa}}=0$ ). As it begins to move, its front velocity is very small, so in the beginning the mass accelerates along the slope until it comes to rest. Following Walder and others (2003), with our dynamic simulation, we investigated the transitional behavior between these flow scenarios. For this, the submerged travel time (depending on the landslide length and height of the reservoir, it could be partial submerged time) is defined as the time taken by the landslide to travel from the shore $(x=160 \mathrm{~m})$ to the horizontal base $(x=200 \mathrm{~m})$ of the reservoir. Due to the acceleration, the characteristic submerged travel times for the landslides released from upslopes may differ from the submerged travel time for the mass released from shoreline.

One of the major challenges associated with the impulsive waves is the proper estimation of the velocity of the slide mass at the impact and during submergence (Slingerland and Voight, 1979). For this reason, subaerial and submarine accelerations are usually assumed to be the same, subject to uncertainty. For a non-deformable solid block, Walder and others (2003) assumed the same characteristic acceleration, $\alpha^{\mathrm{a}}$, for both the subaerial and submarine flows. Nevertheless, the value of $\alpha^{\text {a }}$ for the subaerial motion may be substantially higher than its value for the submarine motion. That could even be so for a deformable two-phase solid-fluid mixture debris flow for which the dynamics is more complicated as it takes into account several driving forces, including friction, viscosity, drag, solid concentration, etc. For this reason, we define subaerial and submarine accelerations, respectively, as $\alpha_{\mathrm{sa}}^{\mathrm{a}}$ and $\alpha_{\mathrm{sm}}^{\mathrm{a}}$.

Let $t_{\mathrm{s} H}$ be the submerged travel time for the landslide released at height $H_{\mathrm{sa}}$, and $t_{\mathrm{ss}}$ be the submerged travel time for the landslide released at the shoreline. Then the ratio between these submerged times is (Walder and others, 2003)

$$
\begin{aligned}
\frac{t_{\mathrm{s} H}}{t_{\mathrm{ss}}} & =\frac{\sqrt{\frac{2}{\sin \zeta}\left(\frac{H_{\mathrm{sm}}}{\alpha_{\mathrm{sm}}^{\mathrm{a}}}+\frac{H_{\mathrm{sa}}}{\alpha_{\mathrm{sa}}^{\mathrm{a}}}\right)}-\sqrt{\frac{2 H_{\mathrm{sa}}}{\alpha_{\mathrm{sa}}^{\mathrm{a}} \sin \zeta}}}{\sqrt{\frac{2 H_{\mathrm{sm}}}{\alpha_{\mathrm{sm}}^{\mathrm{a}} \sin \zeta}}} \\
& =\sqrt{1+\alpha \frac{H_{\mathrm{sa}}}{H_{\mathrm{sm}}}}-\sqrt{\alpha \frac{H_{\mathrm{sa}}}{H_{\mathrm{sm}}}}
\end{aligned}
$$

where $\alpha=\alpha_{\mathrm{sm}}^{\mathrm{a}} / \alpha_{\mathrm{sa}}^{\mathrm{a}}$, so $\alpha \leq 1$. We call $\alpha$ the submerge factor, the ratio between the submarine and subaerial mass accelerations. Equation (12) with $\alpha=1$ reduces to submerge time ratio in Walder and others (2003).

We consider the three simulations I, II and III presented in Figures 2-4. The heights of the mass release are $H_{\mathrm{sa}}=[120,60,0] \mathrm{m}$, and the submarine fluid height is $H_{\mathrm{sm}}=40 \mathrm{~m}$. Based on Eqn (12) we present two alternative analyses for submergence scales.

\section{Motion of submarine maximum height position}

First, we consider the submergence time when the maximum (or at least a substantial amount) of (solid) mass enters the reservoir from the left $(x=160 \mathrm{~m})$, and the time it takes for the maximum position to reach the base $(x=200 \mathrm{~m})$. This can also be considered as the time during which the rate of sediment entry into the reservoir is large. It can also be considered as the time taken by the major portion of the mass to accumulate in this region, or the time for which the position of the maximum (solid) height virtually does not change. These times can be estimated from the solid fraction dynamics in the corresponding figures (right panels). The idea here is to somehow relate the deforming mass to the solid sliding as considered previously (e.g. by Walder and others, 2003), so that the chosen time reflects accurately or reasonably) the motion of the center of mass in the submarine environment. For the mass released from the heights $H_{\mathrm{sa}}=[120,60,0] \mathrm{m}$ these times, as estimated from the simulations, are $1.20 \mathrm{~s}(6.00 \mathrm{~s}-4.8 \mathrm{~s}), 1.50 \mathrm{~s}(5.00 \mathrm{~s}-$ $3.5 \mathrm{~s})$ and $3.65 \mathrm{~s}(3.65 \mathrm{~s}-0.0 \mathrm{~s})$, respectively. Thus, the corresponding submerge times are $t_{\mathrm{s} H}=[1.2,1.5,3.65] \mathrm{s}$, 


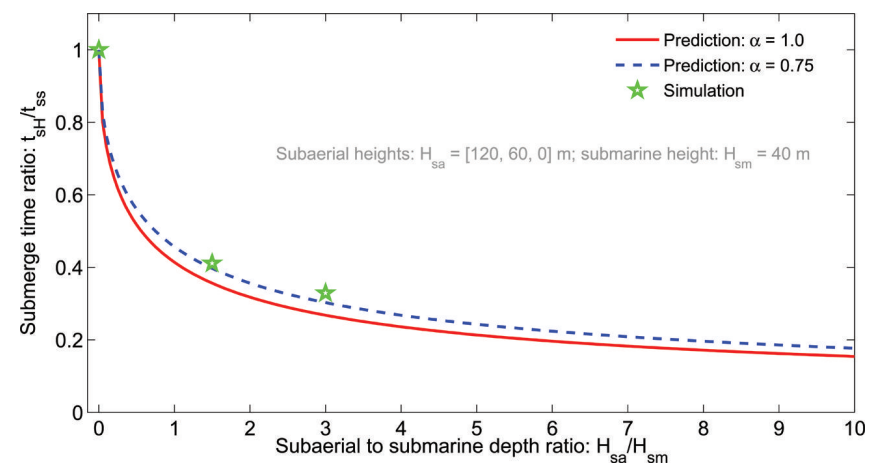

Fig. 5. The submerge time ratios $t_{\mathrm{sH}} / t_{\mathrm{ss}}$ as a function of the ratio of subaerial height to the submarine depth $H_{\mathrm{sa}} / H_{\mathrm{sm}}$ associated with the motion of submarine maximum height position that relates to the bulk-type motion.

respectively, where $t_{\mathrm{sH}}=t_{\mathrm{ss}}$ for $t_{\mathrm{sH}}=3.65 \mathrm{~s}$. The submerge time ratios thus obtained from our simulations as a function of the ratio of subaerial height to the submarine fluid depth are shown as green star symbols in Figure 5. The submerge time ratio $t_{\mathrm{sH}} / t_{\mathrm{sS}}$ as a function of the ratio of the subaerial height to the submarine fluid depth $H_{\mathrm{sa}} / H_{\mathrm{sm}}$ as predicted by Eqn (12) is also shown in Figure 5. The red solid line is the prediction with $\alpha=1.0$ that corresponds to Walder and others (2003), and the blue dashed line is the prediction with $\alpha=0.75$ that fits well with our simulation. For this analysis considering the motion of submarine maximum height position, the submerge time ratio model presented by Walder and others (2003) works very well.

\section{Motion of the submarine debris front position}

The second analysis concerns the motion of the submarine debris front position as it enters from the left and flows to the base of the reservoir. On one hand, from the simulation, we obtain the corresponding submerge times for the front positions as $t_{\mathrm{s} H}=[0.9,1.2,1.9] \mathrm{s}$, respectively, where $t_{\mathrm{sH}}=t_{\mathrm{ss}}$ for $t_{\mathrm{sH}}=1.9 \mathrm{~s}$. These times are estimated from simulations when the solid phase height is $\sim 1 \mathrm{~m}$ at the left shore, i.e. debris entering the reservoir $(4.0 \mathrm{~s}, 2.1 \mathrm{~s}, 0.0 \mathrm{~s})$, and reaching its base $(4.9 \mathrm{~s}, 3.3 \mathrm{~s}, 1.9 \mathrm{~s})$, respectively. These estimates are reasonable, because the solid height in the initial reservoir is $0.8 \mathrm{~m}$. The submerge time ratios thus obtained from our simulations as a function of the ratio of subaerial height to the submarine fluid depth are shown as green star symbols in Figure 6. On the other hand, the submerge time ratio $t_{\mathrm{sH}} / t_{\mathrm{ss}}$ as a function of the ratio of subaerial height to the submarine fluid depth $H_{\mathrm{sa}} / H_{\mathrm{sm}}$ as predicted by Eqn (12) is also shown in Figure 6. The red solid line is the prediction with $\alpha=1.0$ that corresponds to Walder and others (2003), and the blue dashed line is the prediction with $\alpha=0.2$ that fits well with our simulation. This figure shows that the subaerial mass acceleration can be much higher than the submarine mass acceleration. Although this time ratio drops significantly for $H_{\mathrm{sa}} / H_{\mathrm{sm}}>1$, it is still substantially higher for $\alpha=0.2$ than for $\alpha=1.0$. These differences might have originated due to the higher slope, relatively shallow debris at the time of impact, energy dissipation due to viscous, frictional and drag forces, phase interactions, etc. This indicates that the submerge timescaling for deformable two-phase debris mass flow may deviate substantially from the submerge timescaling for nondeformable solid mass motion.

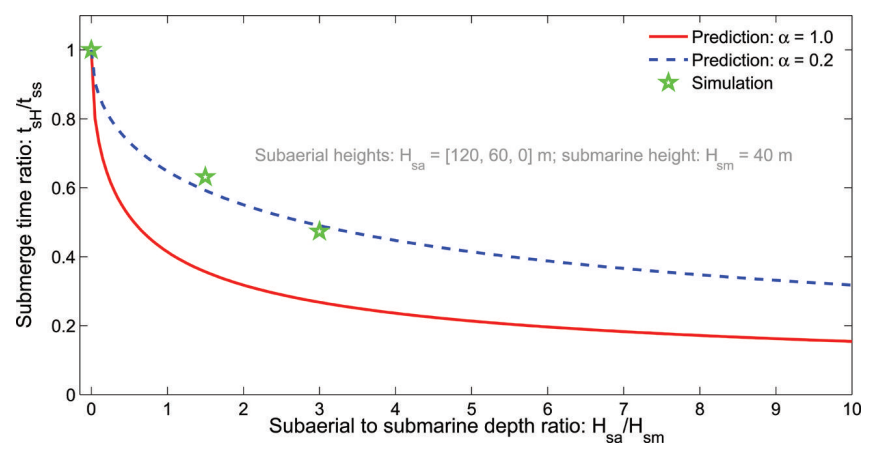

Fig. 6. The submerge time ratios $t_{\mathrm{sH}} / t_{\mathrm{ss}}$ as a function of the ratio of subaerial height to the submarine depth $H_{\mathrm{sa}} / H_{\mathrm{sm}}$ associated with the motion of the deformable submarine debris front position.

Accurate knowledge of the submerge time is essential for the proper description of the submarine mass movements. However, Slingerland and Voight (1979) and Walder and others (2003) mentioned that experimental determination of the submerged travel time is challenging because neither the impact nor the stoppage of the landslide can be accurately determined. Although these times can be obtained by interpolations, the results are subject to substantial errors. In combination with the scaling law (Eqn (12)) our simulations can be applied to more appropriately determining the impact and submarine stoppage times. Furthermore, typically splash-zone dynamics (Walder and others, 2003) can be properly described by numerical models that fully account for a coupling between solid and fluid motion. Our dynamic simulations can thus be useful in overcoming uncertainty associated with the velocity estimation at the time of landslide impact and entry into the fluid body (Slingerland and Voight, 1979).

\section{SUMMARY}

Our results focus on the simultaneous dynamic simulation of 3-D and real two-phase subaerial and submarine landslide and debris flows; the resulting tsunami generation and propagation upon debris impact on the water body; the subsequent submarine landslide, debris flow, turbidity current and particle transport in the fluid; and the analysis of all three types of waves and their complex interactions. The general two-phase physical-mathematical mass flow model proposed by Pudasaini (2012) is solved numerically by applying a high-resolution shock-capturing numerical scheme. These innovative and unified approaches (Pudasaini, 2014) allow for the adequate modeling of debrisinduced tsunami and submarine sediment transport.

The simulation results show that when a real two-phase debris mass slides down an inclined plane, it spreads downslope and cross-slope. When the sliding debris mass hits the reservoir, tsunami waves are generated in the vicinity of the impact and are amplified when the fluid mass is pushed forward, and a 3-D hydrodynamic impact vacuum is created. The tsunami waves propagate in all three directions. The solid mass forms a very special (not observed before) forward-propagating cone-shaped solid wave.

We analyzed in detail how the positions of initial debris mass on the inclined slope influence the splash, tsunami generation and submarine debris mass movements. This 
includes mass spreading and accelerations in both the subaerial and submarine environments, impact and submergence times and scalings.

For the mass released from upslope, the debris is laterally more spread both on the subaerial and submarine parts of the incline. Therefore, the tsunami amplifications are similar to those for the mass released from the middle of the slope. This spreading results in submarine front and rear positions much closer to each other than for the same mass released from the middle of the slope. The submarine solid structures are fundamentally different for different initial mass positions. The submarine solid mass is much more elongated across slope for the mass released from the top. Similarly, the dynamics of the position of maximum submarine solid height depends strongly on the subaerial initial mass positions. The longitudinal extent of the submarine debris is substantially shorter for the mass released from the top than from the middle. For the mass released from the middle of the slope the submarine solid mass is largely elongated in the downslope direction, with the major portion lying before the reservoir base, whereas for the flow released from the top the submarine mass is largely sheared and elongated in the cross-slope direction, forming a transverse wall close to the base.

For the mass released from the shore, there are further interesting observations. The dynamics is smoother than in the previous cases in which the landslide impacts were more intensive. For this, the motion is pressure-driven, with less inertia in the inception of the motion resulting in the low-extent tsunami. The impulsive pressure exerted by the much thicker debris material on the reservoir fluid is the main initial mechanism in tsunami generation here, whereas in the previous cases tsunamis were generated by strong impact of rapidly cascading relatively thin subaerial debris. Due to the low momentum and drag, for this mass release, the front propagated much farther with diffusive and dilute turbidity currents. Consequently, the submarine deposition process began much earlier. The main deposition developed into a backward-propagating shock wave, much stronger and more localized than in other mass flows released from upslope. Interestingly, the major portion of the solid mass is elongated in the cross-slope whereas the dispersed and dilute mass is elongated in the downslope direction.

We presented two alternative analyses for submergence timescales: the motion of submarine maximum height position that relates to the bulk-type motion, and the motion of the submarine debris front position associated with the deformable debris motion. We show that the subaerial mass acceleration can be much greater than the submarine mass acceleration. This led to the conclusion that the submerge timescaling for deformable two-phase debris mass flow may deviate substantially from the submerge timescaling for nondeformable solid mass. Thus, our simulations, which adequately account for a coupling between solid and fluid motion, can be applied to more appropriately determining the impact and submarine stoppage times, and describing the splash-zone and far-field dynamics.

These results can be applied to properly analyze the stability of reservoir dams, embankments and slopes in response to the fluctuation of the water level due to landslide impact (Khattri, 2014). This unified model and computational technique with innovative approach allows for the adequate modeling of debris-induced tsunami and submarine sediment transport, with significant applications in hazard mitigation, sedimentology, submarine geodynamics, the integrity of hydroelectric power plants and safety aspect during and after construction of large artificial reservoirs.

\section{ACKNOWLEDGEMENTS}

We thank the anonymous reviewers, the Scientific Editor Nicolas Eckert and the Chief Editor Graham Cogley for constructive comments that helped to improve the manuscript. Shiva P. Pudasaini acknowledges the financial support provided by the German Research Foundation (DFG) through the research project, PU 386/3-1: 'Development of a GIS-based Open Source Simulation Tool for Modelling General Avalanche and Debris Flows over Natural Topography' within a transnational research programme, D-A-CH.

\section{REFERENCES}

Abadie S, Morichon D, Grilli S and Glockner S (2010) Numerical simulation of waves generated by landslides using a multiplefluid Navier-Stokes model. Coastal Eng., 57(9), 779-794

Ataie-Ashtiani B and Nik-Khah A, (2008) Impulsive waves caused by subaerial landslides. Environ. Fluid Mech., 8, 263-280 (doi: 10.1007s10652-008-9074-7)

Ataie-Ashtiani B and Shobeyri G (2008) Numerical simulation of landslide impulsive waves by incompressible smoothed particle hydrodynamics. Int. J. Num. Meth., 56, 209-232

Cecioni C (2010) Numerical modeling of waves for a tsunami early warning system. (PhD thesis, Universita degli Studi Roma Tre)

Didenkulova I, Nikolkina I, Pelinovsky E and Zahibo N (2010) Tsunami waves generated by submarine landslides of variable volume: analytical solutions for a basin of variable depth. Natur. Hazards Earth Syst. Sci., 10, 2407-2419 (doi: 10.5194/nhess10-2407-2010)

Domnik B, Pudasaini SP, Katzenbach R and Miller SA (2013) Coupling of full two-dimensional and depth-averaged models for granular flows. J. Non-Newtonian Fluid Mech., 201, 56-68

Enet F, Grilli ST and Watts P (2003) Laboratory experiments for tsunamis generated by underwater landslides: comparison with numerical modeling. Proceedings of the 13th Offshore and Polar Engineering Conference, 3, 372-379

Fritz HM and Kalligeris N (2008) Ancestral heritage saves tribes during 1 April 2007 Solomon Islands tsunami. Geophys. Res. Lett., 35 (doi: 10.1029/2007GL031654)

Fritz HM, Hager WH and Minor HE (2001) Lituya Bay case: rockslide impact and wave run-up. Sci. Tsunami Hazards, 19, $3-22$

Fritz HM, Hager WH and Minor HE (2003) Landslide generated impulse waves. 2. Hydrodynamic impact craters.Exp. Fluids, 35, 520-532 (doi: 10.1007s00348-003-0660-7)

Fritz HM, Hager WH and Minor HE (2004) Near field characteristics of landslide generated impulse waves. J. Waterway Port, Coast. Ocean Eng., 130(6), 287-302 (doi: 10.1061(ASCE)0733950X)

Fritz HM, Mohammed F and Yoo J (2009) Lituya Bay landslide impact generated mega-tsunami 50th anniversary. Pure Appl. Geophys, 116, 1-2

Glicken H, Meyer W and Sabol M (1989) Geology and groundwater hydrology of Spirit Lake blockage, Mount St. Helens, Washington, with implications for lake retention. US Geophys. Surv. Bull., 33

Gray JMNT (2001) Granular flow in partially filled slowly rotating drums. J. Fluid Mech., 441, 1-29

Greve R and Hutter K (1993) Motion of a granular avalanche in a convex and concave curved chute: experiments and theoretical predictions. Philos. Trans. R. Soc. London, 342, 573-600 
Grilli ST, Vogelmann S and Watts P (2002) Development of a 3D numerical wave tank for modeling tsunami generation by underwater landslides. Eng. Anal. Bound. Elem., 26, 301-313

Grilli ST, loualalen M, Asavanant J, Shi F, Kirby J and Watts P (2007) Source constraints and model simulation of the December 26, 2004, Indian Ocean tsunami. J. Waterw. Port Coast. Ocean Eng., 133, 414-428

Hampton MA, Lee HJ and Locat J (1996) Submarine landslides. Rev. Geophys., 34, 33-59

Haugen KB, Lovholt F and Harbitz CB (2005) Fundamental mechanisms for tsunami generation by submarine mass flows in idealised geometries. Mar. Petrol. Geol., 22(1-2), 209-217

Heinrich P (1992) Nonlinear water waves generated by submarine and aerial landslides. J. Waterw. Port Coast. Ocean Eng., 118, 249-266

Heinrich P, Piatanesi A and Hebert H (2001) Numerical modeling of tsunami generation and propagation from submarine slumps: the 1998 Papua New Guinea events. Geophys. J. Int., 145, 97-111

Iverson RM (1997) The physics of debris flows. Rev. Geophys., 35(3), 245-296

Iverson RM and Denlinger RP (2001) Flow of variably fluidized granular masses across three-dimensional terrain: 1. Coulomb mixture theory. J. Geophys. Res., 106(B1), 537-552

Kafle J (2014) Dynamic interaction between a two-phase submarine landslide and a fluid reservoir. (MPhil thesis, Kathmandu University)

Kamphuis JW and Bowering RJ (1972) Impulse waves generated by landslides. Proceedings of the 11th Coastal Engineering Conference, 575-588

Kattel P (2014) Dynamics of quasi-three-dimensional and twophase mass flows. (MPhil thesis, Kathmandu University)

Khattri KB (2014) Sub-diffusive and sub-advective viscous fluid flows in debris and porous media. (MPhil thesis, Kathmandu University)

Law L and Brebner A (1989) On water waves generated by landslides. (Paper 2561) Third Australasian Conference on Hydraulics and Fluid Mechanics. Institute of Engineering, Sydney

Legros F (2002) The mobility of long-runout landslides. Eng. Geol., 63, 301-331

Liu JF, Mauzerall DL and Horowitz LW (2005) Analysis of seasonal and interannual variability in transpacific transport. J. Geophys. Res. Atmos., 110 (doi: 10.10292004JD005207)

Masson DG, Harbitz CB, Wynn RB, Pedersen G and Lovholt F (2006) Submarine landslides: processes, triggers and hazard prediction. Philos. Trans. R. Soc. London, 364, 2009-2039

Miao H, Wang G, Yin K, Kamai T and Li Y (2014) Mechanism of the slow-moving landslides in Jurassic red-strata in the Three Gorges Reservoir, China. Eng. Geol., 171, 59-69 (doi: 10.1016j. enggeo.2013.12.017)

Miller J (1960) Giant waves in Lituya Bay, Alaska. Geol. Surv. Prof. Paper, 354-C(1), 107-144

Miller L (1964) The rock slide in the Vajont Valley. Rock Mech. Eng. Geol., 2(3-4), 148-212

Mohammed F and Fritz HM (2012) Physical modeling of tsunamis generated by three-dimensional deformable granular landslides. J. Geophys. Res., 117, 705-718, C11015 (doi: 10.1029/ 2011JC007850)

Monaghan JJ and Kos A (2000) Scott Russell's wave generator. Phys. Fluids, 12, 622-630

Murty TS (1979) Submarine slide-generated water waves in Kitimat Inlet, British Columbia. J. Geophys. Res., 84, 7777-7779 (doi: 10.1029JC084iC12p07777)

Nessyahu H and Tadmor E (1979) Non-oscillatory central differencing for hyperbolic conservation laws. J. Comput. Phys., 87(2), 408-463
Pelinovsky E and Poplavsky A (1996) Simplified model of tsunami generation by submarine landslide. Phys. Chem. Earth, 21(12), 13-17

Petrakov DA and 9 others (2011) Monitoring of Bashkara glacier lakes (Central Caucasus, Russia) and modeling of their potential outburst. Natur. Hazards, 58(2), 609-619 (doi: 10.1007/ s11069-011-9983-5)

Pitman EB and Le L (2005) A two fluid model for avalanche and debris flows. Philos. Trans. R. Soc. London, 363(3), 1573-1601

Pudasaini SP (2012) A general two-phase debris flow model. J. Geophys. Res., 117, F03010 (doi: 10.1029/2011JF002186)

Pudasaini SP (2014) Dynamics of submarine debris flow and tsunami. Acta Mech., 225, 2423-2434 (doi: 10.1007/s00707014-1126-0)

Pudasaini SP and Hutter K (2003) Rapid shear flows of dry granular masses down curved and twisted channels. J. Fluid Mech., 295 193-208

Pudasaini SP and Hutter K (2007) Avalanche dynamics: dynamics of rapid flows of dense granular avalanches. Springer, Berlin and New York

Pudasaini SP and Krautblatter M (2014) A two-phase mechanical model for rock-ice avalanches. J. Geophys. Res. Earth Surf., 119 (doi: 10.1002/2014JF003183)

Pudasaini SP and Miller SA (2012) A real two-phase submarine debris flow and tsunami. AIP Conf. Proc. 1479, 197-200 (doi: 10.1063/1.4756096)

Pudasaini SP, Wang Y and Hutter K (2005) Modelling debris flows down general channels. Natur. Hazards Earth Syst. Sci., 5, 799-819

Pudasaini SP, Kattel P, Kafle J, Pokhrel PR and Khattri KB (2014) Two-phase and three-dimensional simulations of complex fluidsediment transport down a slope and impacting water bodies. Geophys. Res. Abstr., 16, EGU2014-5084

Sammarco P and Renzi E (2008) Landslide tsunamis propagating along a plane beach. J. Fluid Mech., 598, 107-119 (doi: 10.1017S0022112007009731)

Savage SB and Hutter K (1989) The motion of a finite mass of granular material down a rough incline. J. Fluid Mech., 199, 177-215

Savage SB and Hutter K (1991) Dynamics of avalanches of granular materials from initiation to runout. Part I: Analysis. Acta Mech., 86, 201-223

Shrestha AB, Eriksson M, Mool P, Ghimire P Mishra B and Khanal NR (2010) Glacial lake outburst flood risk assessment of Sun Koshi Basin, Nepal. Geomat. Natur. Hazards Risk, 1(2)

Slingerland RL and Voight B (1979) Occurrences, properties, and predictive models of landslide-generated water waves. Elsevier, Amsterdam, 317-397

Tai YC, Noelle S, Gray JMNT and Hutter K (2002) Shock-capturing and front-tracking methods for granular avalanches. J. Comput. Phys., 175(1), 269-301

Viroulet S, Cebron D, Kimmoun O and Kharif C (2013) Shallow water waves generated by subaerial solid land-slides. Geophys. J. Int., 193, 747-762 (doi: 10.1093gjiggs133)

Walder JS, Watts P, Sorensen OE and Janssen K (2003) Tsunamis generated by subaerial mass flows. J. Geophys. Res., 108(5), 2236-2255

Watts P (1997) Water waves generated by underwater landslides. (PhD thesis, California Institute of Technology)

Watts P and Walder JS (2003) Evaluating tsunami hazards from debris flows. Proceedings of the 3rd International Conference on Debris-Flow Hazards Mitigation. Swiss Federal Institute for Snow and Landscape Research, Davos, 10-12

Worni R, Stoffel M, Huggel C, Volz C, Casteller A and Luckman B (2012) Analysis and dynamic modeling of a moraine failure and glacier lake outburst flood at Ventisquero Negro, Patagonian Andes (Argentina). J. Hydrol., 444-445, 134-145. 